\title{
SAR Evaluation of Metallic Loop-like Accessory Effect of Broadband Wearable Planar Monopole Textile Antenna
}

\author{
H. H. Zainal ${ }^{1}$, H. A. Rahim ${ }^{1}$, P. J. Soh ${ }^{2}$, H. Lago ${ }^{2}$, K.N.Abdul Rani ${ }^{3}$, M. S. \\ Zulkefli $^{4}$, Y. S. Lee ${ }^{3}$ and N. F. N. Yah ${ }^{1}$ \\ ${ }^{1}$ Bioelectromagnetics Research Group (BioEM), \\ ${ }^{2}$ Advanced Communication Engineering (ACE), \\ School of Computer and Communication Engineering, Universiti Malaysia Perlis (UniMAP), Kampus \\ Pauh Putra, Perlis, Malaysia \\ ${ }^{3}$ Faculty of Technology Engineering Universiti Malaysia Perlis (UniMAP), Padang Besar \\ Perlis,Malaysia \\ ${ }^{4}$ Centre for Diploma Studies (CDS),Universiti Malaysia Perlis (UniMAP), Campus UniCITI Alam Sg. \\ Chuchuh,Perlis,Malaysia \\ *corresponding author:haslizarahim@unimap.edu.my
}

\begin{abstract}
This paper presents the investigation of influence of the common metallic loop-like accessory on the Specific Absorption Rate (SAR) averaged over $10 \mathrm{~g}$ and $1 \mathrm{~g}$ of body tissue. The simulations were made by means of CST Microwave Studio software at frequencies of $2.45 \mathrm{GHz}$ and 2.6GHz. Numerical analysis conducted using a broadband textile monopole antenna (TM) with variations of orientation and distance showed that SAR values increased when the TM is horizontally polarized. This is up to $80 \%$ more than vertically polarized TM when placed closest to the metallic item at $2 \mathrm{~mm}$.
\end{abstract}

\section{Introduction}

The growing usage of mobile phones and electronic devices has raised public concerns about the possible health effects of electromagnetic (EM) radiation of these devices on user [1]. The effects of radio frequency (RF) includes the rise of the body temperature and, which potentially affects the eyes, brain and other sensitive areas [2].

Many studies have been conducted to examine the effects of metallic objects on SAR distribution, metallic objects on the resulting SAR values [3]. A more recent study [4] found that the values of the SAR on the existence of antenna ground plane besides antenna-to-phantom is seen to be quite linearly decrease with increasing distances. However, to the best of authors' knowledge, a thorough experimental investigation of the influence of metallic body accessory on the SAR of on-body wearable antenna has yet to be reported in the open literature. It was hypothesized that the presence of metallic body accessories may affect the
SAR values when the on-body wearable antenna was mounted in the close proximity to the human body. Besides, numerous studies reported that significant changes in obtained SAR values were observed when placing the metallic implant within the tissue [1, 5-7]. The presence of the implant leads to strong increase in SAR up to $30 \%$ and $13 \%$ maximum SAR occurred at 1,800 and $900 \mathrm{MHz}$ [1]. On the contrary, the distance between the antenna and torso, as well as the polarization of antenna affect the level of radiation, electric (E) - field [7].

The authors evaluated the $1 \mathrm{~g}$ SAR when exposed to mobile phone in the vicinity of circular metallic jewelry. It was reported that $1 \mathrm{~g}$ SAR was increased by approximately 7.4 times from 0.50 to $3.70 \mathrm{~W} / \mathrm{kg}$ when circular metallic jewelry is placed in-between the phantom and the RF source [8].

\section{Specific absorption rate}

The SAR parameter is used to measure the amount of energy absorbed by a biological tissue when electromagnetic induction is present. A high SAR esteem shows a high measure of radiation absorbed by the tissue. The SAR can also be defined mathematically as shown in the following equation [9]:

$$
\mathrm{SAR}=\frac{\sigma|E|^{2}}{\rho} \quad(W / k g)
$$


where $\mathrm{E}$ is the electric field induced in the tissue, $(\mathrm{V} / \mathrm{m}), \sigma$ is the conductivity of the tissue, $(\mathrm{S} / \mathrm{m})$ and $\rho$ is the tissue density, $\left(\mathrm{kg} / \mathrm{m}^{3)}[10]\right.$. The SAR is expressed in watts per kilogram $(\mathrm{W} / \mathrm{kg})$. The SAR limit is different in different regions and it is based on the standardization committee. In the US for mobile phones is $1.6 \mathrm{~W} / \mathrm{kg}$, averaged over 1 gram of tissue. But in Europe, the SAR limit is $2.0 \mathrm{~W} / \mathrm{kg}$ averaged over 10 grams of tissue [11].

\section{Cylindrical phantom model}

In order to investigate the interaction between the antenna and the human body in the presence of metallic loop like accessory, cylindrical phantom model is used in the simulation to represent the structure of human body. Cylindrical phantom model are shown in Figure 1. The parameters $(\varepsilon r, \sigma)$ of human body tissues are defined according the standard tissue equivalent liquids recommended by the Electrical and Electronics Engineers (IEEE) and Federal Communications Commission FCC [3]. This cylindrical phantom model is used in the simulation to estimate the SAR values. Cylindrical phantom model with details different body mass index (BMI) dimensions are based on the average of six subjects with body circumferences as in shown in [12].

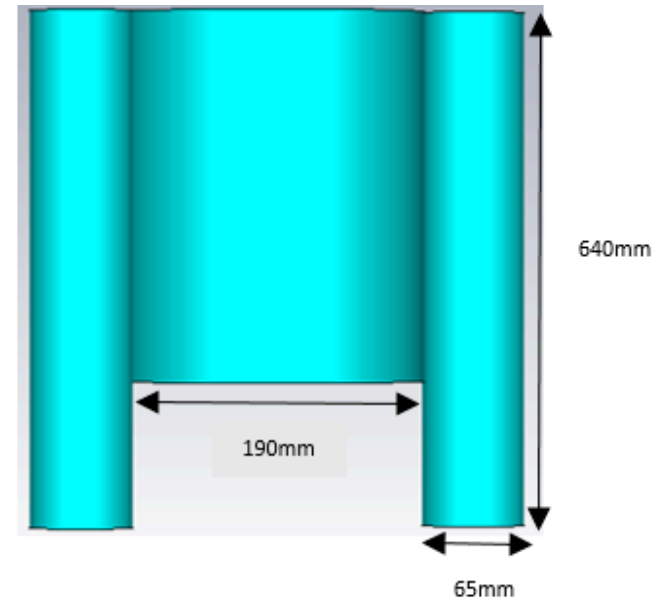

Figure 1: Cylindrical Phantom model

\section{Metallic specification and simulation setup}

\subsection{Metallic loop like accessory}

In order to investigate the effect by the presence of metallic loop-like accessory in close proximity of the transmitting antenna, the metallic loop like accessory is modeled as silver $\left(6.30 \times 10^{7}\right)$. The loop-like accessory is modeled with outer radius of $68 \mathrm{~mm}$ and inner radius of $64 \mathrm{~mm}$. The width of metallic loop like accessory is $18 \mathrm{~mm}$. This size is based on wrist of cylindrical phantom model.

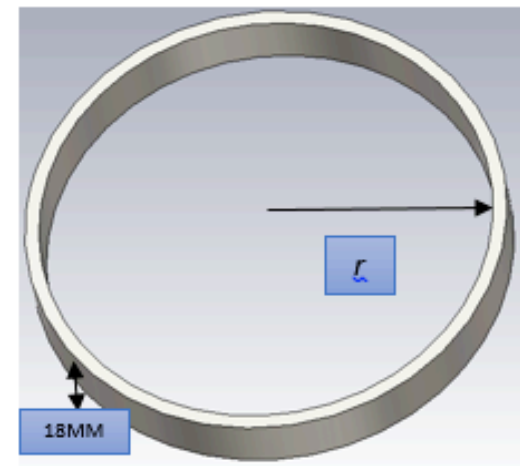

Figure 2 : Metallic Loop Like Accessory

\subsection{Simulation Setup}

A N/4 planar monopole textile antenna (TM) as the transmitting antenna is used which was based on the work presented in [12]. This wearable textile monopole has a broad bandwidth characteristic of over $700 \mathrm{MHz}$, operating from $2.3 \mathrm{GHz}$ to $3.0 \mathrm{GHz}$. where ShieldIt Super is used as conducting element and felt fabric as substrate element, see Figure 3.
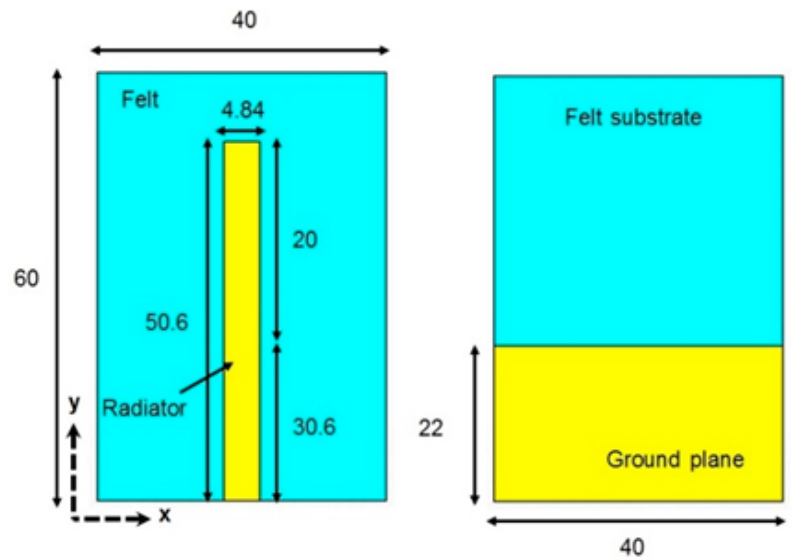

(a) 

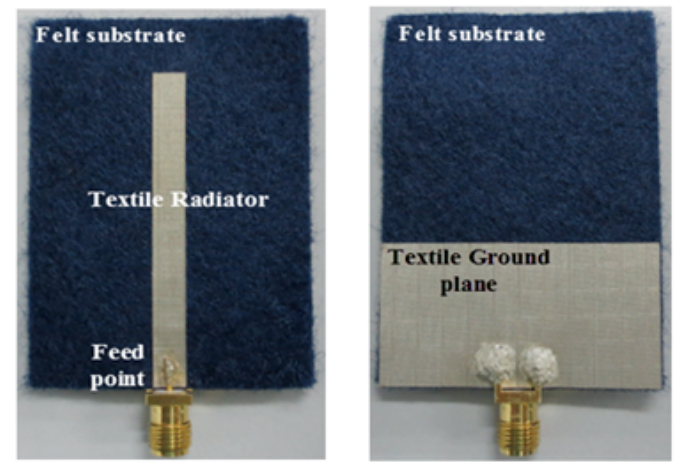

(b)

Figure 3: Structure and dimensions of (a) planar TM in millimeters and its (b) fabrication prototype in front and back views [13].

Numerical simulations are conducted using CST Microwave Studio based on the Finite Integral Technique (FIT). The generic human body consists of three cylindrical bricks, representing the upper human body torso and two arms. Such type of antenna is chosen due to its partial ground plane that allows radiation towards the human body. The TM is positioned against the metallic loop-like accessory, placed on the left wrist of the generic arm at a distance of between $2 \mathrm{~mm}$ until $20 \mathrm{~mm}$ away from the phantom.

The RF energy absorption is evaluated when the antenna is placed in varied distances from metallic item in two different orientations (vertical and horizontal polarizations with respect to the phantom body model). Firstly, the cylindrical phantom model is simulated with the planar $\lambda / 4 \mathrm{TM}$ antenna in free space. The metallic loop like accessory is positioned $2 \mathrm{~mm}$ away from the cylindrical phantom as the shortest distance considering the thickness of the shirt.

The antenna input power is normalized to $1 \mathrm{~W}$. The simulation setup for cylindrical phantom model are shown in Figure 4. Each simulation generated c.a. 41 million mesh cells and is executed using a workstation with an Intel ${ }^{\circledR}$ Xeon ${ }^{\circledR}$ E5506, $2.13 \mathrm{GHz}$ processor, $48 \mathrm{~GB}$ RAM and an NVIDIA GeForce GTX 1050 Graphic Processing Unit (GPU).

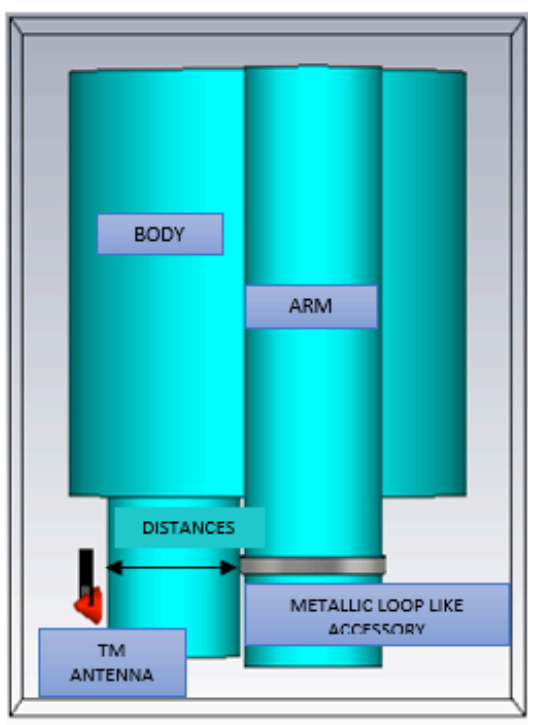

Figure 4 : Simulation setup of TM antenna in the presence of cylindrical phantom model and metallic ring.

\section{Results and discussion}

\subsection{Antenna reflection coefficient}

Figure 5 and 6 show the variations on antenna resonant frequency due to the presence of metallic loop like accessory at $2.45 \mathrm{GHz}$ and $2.6 \mathrm{GHz}$ respectively. It can been clearly seen that the $S_{11}$ variation depends on the distance of the antenna from the metallic loop like accessory .The worst case of $S_{11}$ is observed when TM is horizontal polarization, which is parallel to the human body model with the distance to the metallic item, i.e, $8 \mathrm{~mm}$ and $12 \mathrm{~mm}$. Figure 5 shows the $\mathrm{S}_{11}$ value decreases by $62 \%$ when the antenna is in vertical condition for the $8 \mathrm{~mm}$ distances at frequency 2.45 GHz. Whereas in Figure 6, the decrease between with and without metallic loop like accessory for vertical polarization is $46 \% . S_{11}$ value decreases when the vertically orientation at both frequencies $2.45 \mathrm{GHz}$ and $2.6 \mathrm{GHz}$. 


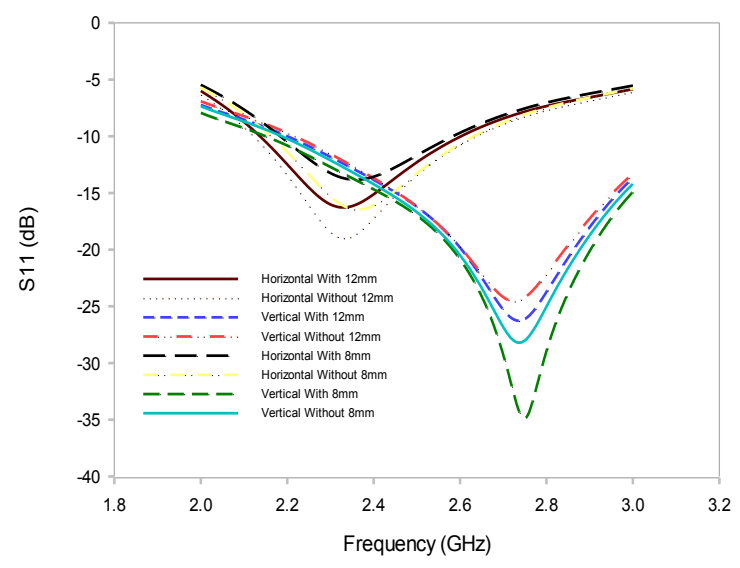

Figure $5: \mathrm{S}_{11}$ at $2.45 \mathrm{GHz}$

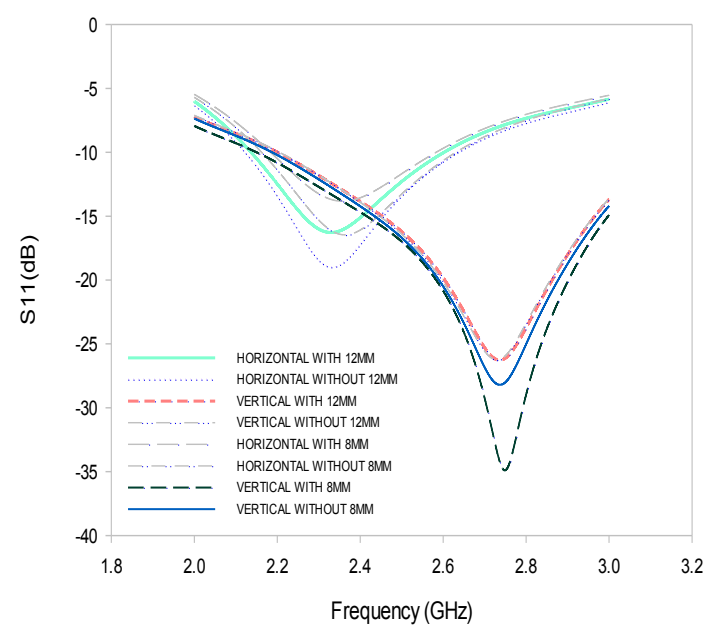

Figure 6: $\mathrm{S}_{11}$ at $2.6 \mathrm{GHz}$

\subsection{SAR for broadband TM}

In this paper, the amount of energy absorbed by the body is discussed in term of $10 \mathrm{~g}$ and $1 \mathrm{~g}$ SAR. Figure 7 and 8 show the maximum $10 \mathrm{~g}$ and $1 \mathrm{~g}$ SAR value inside the human body for different antenna orientations and distances antenna from metallic item at both $2.45 \mathrm{GHz}$ and $2.6 \mathrm{GHz}$. Figure 7 shows the $10 \mathrm{~g}$ SAR value inside the human body. The lowest SAR value is observed when the antenna vertically positioned at $2.6 \mathrm{GHz}$ and placed $20 \mathrm{~mm}$ from the metallic loop like accessory which is $0.42 \mathrm{~W} / \mathrm{Kg}$. It shows the antenna orientation could decrease the SAR value by approximately 6 times compared to horizontally case $(2.66 \mathrm{~W} / \mathrm{Kg})$ at position $20 \mathrm{~mm}$. At frequency $2.45 \mathrm{GHz}$, the result showed significant difference in the SAR value in position $12 \mathrm{~mm}$ when horizontally orientation which is $7.77 \mathrm{~W} / \mathrm{Kg}$ of about 10 times higher than vertically orientation antenna $(0.77$ $\mathrm{W} / \mathrm{Kg}$ ). Besides, Figure 8 shows the $1 \mathrm{~g}$ SAR value inside the human body at distance $12 \mathrm{~mm}$ in horizontally orientation is $15.67 \mathrm{~W} / \mathrm{Kg}$ but in vertically orientation is $1.22 \mathrm{~W} / \mathrm{Kg}$. It can be concluded that horizontally orientation of $\mathrm{TM}$ increases almost $81 \%$ compared to vertically orientation at frequency $2.45 \mathrm{GHz}$. Overall, it can be observed that, the SAR values remain unchanged in vertical polarization regardless of the TM distances against the metallic loop like accessory.

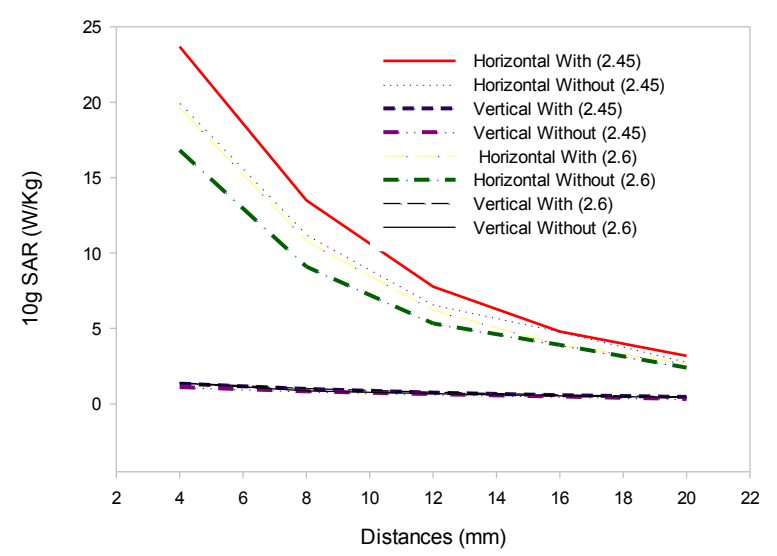

Figure 7: Result of $10 \mathrm{~g} \mathrm{SAR}$ at $2.45 \mathrm{GHz}$ and $2.6 \mathrm{GHz}$

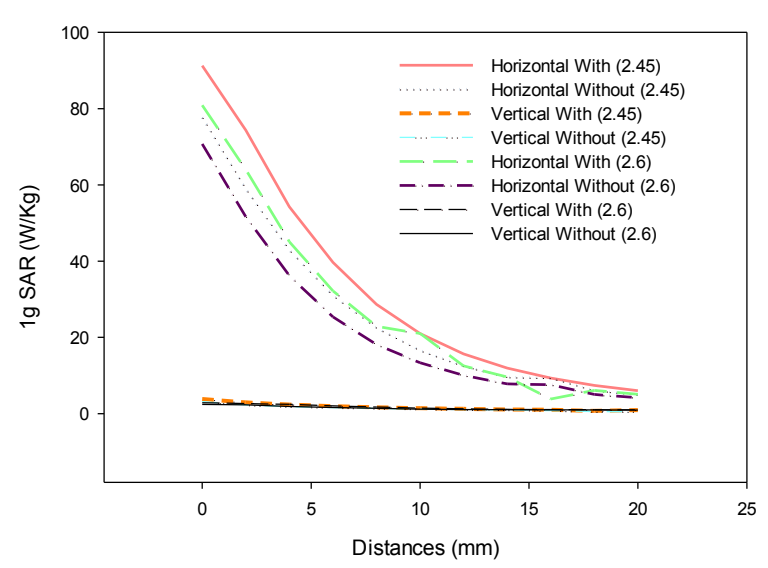

Figure 8: Result of $1 \mathrm{~g} \mathrm{SAR}$ at $2.45 \mathrm{GHz}$ and $2.6 \mathrm{GHz}$ 


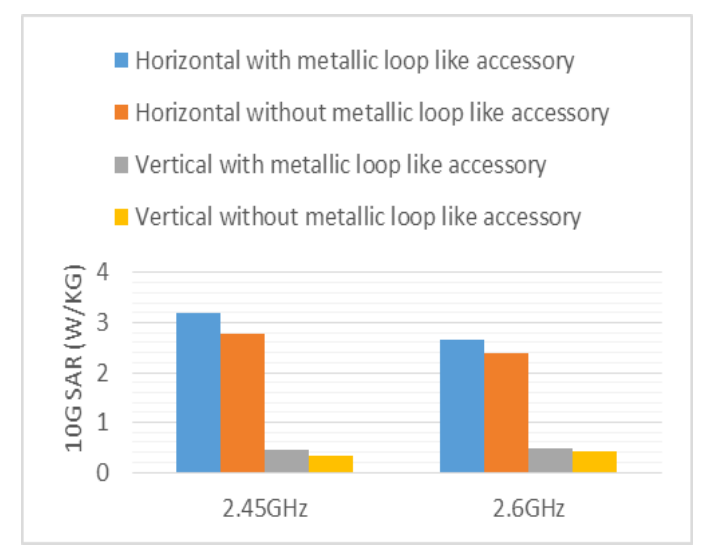

Figure 9: The effect of metallic loop like accessory $20 \mathrm{~mm}$ distance on $10 \mathrm{~g} \mathrm{SAR}$ at $2.45 \mathrm{GHz}$ and $2.6 \mathrm{GHz}$.

Figure 9 shows the presence of metallic loop like accessory gives rise to the SAR values. The amount of absorption increases when the antenna is mounted in the close proximity to metallic loop like accessory at $20 \mathrm{~mm}$. Based on the Figure 9 at frequency $2.6 \mathrm{GHz}$, value SAR before attached the metallic loop like accessory is $2.38 \mathrm{~W} / \mathrm{Kg}$, but after attached the metallic loop like accessory, the value increased to $2.66 \mathrm{~W} / \mathrm{Kg}$, up to $10 \%$. Meanwhile, at frequency $2.45 \mathrm{GHz}$, value of SAR before attached with metallic loop like accessory is $2.78 \mathrm{~W} / \mathrm{Kg}$ and after attached the value SAR increased to $3.18 \mathrm{~W} / \mathrm{Kg}$, up to $12 \%$. The presence of the metallic loop like accessory in close proximity to human body increases the SAR value. Based on the simulated results in Table 1, the amount of energy absorbed when $10 \mathrm{~g}$ (without metallic item) is decreasing $14 \%$ with the increasing frequency from $2.45 \mathrm{GHz}$ to 2.6 GHz. In addition, the presence of metallic item produces slightest effect on SAR value when $10 \mathrm{~g}$ and vertically orientation.

Table 1: The Max SAR value in the presence of metallic loop like accessory at distance $20 \mathrm{~mm}$.

\begin{tabular}{|l|c|c|c|c|}
\hline \multicolumn{5}{|c|}{ Distance $=\mathbf{2 0 m m}$} \\
\hline & \multicolumn{2}{|c|}{$\mathbf{2 . 4 5} \mathbf{G H z}$} & \multicolumn{2}{c|}{$\mathbf{2 . 6 G H z}$} \\
\hline $\begin{array}{l}\text { Horizontal with } \\
\text { metallic loop like } \\
\text { accessory }\end{array}$ & 6.03 & 3.18 & 5.03 & 2.66 \\
\hline $\begin{array}{l}\text { Horizontal } \\
\text { without metallic } \\
\text { loop like } \\
\text { accessory with }\end{array}$ & 0.94 & 0.45 & 0.96 & 0.47 \\
\hline $\begin{array}{l}\text { Vertical log } \\
\text { metallic loop like } \\
\text { accessory }\end{array}$ & & 2.78 & 4.16 & 2.38 \\
\hline $\begin{array}{l}\text { vertical without } \\
\text { metallic loop like } \\
\text { accessory }\end{array}$ & 1.03 & 0.34 & 0.94 & 0.42 \\
\hline
\end{tabular}

\section{Conclusions}

The results presented in this paper are solely based on computer simulation using commercially software CST Microwave Studio. In this work, a monopole antenna has been used as the radiating sources. This study has indicated the additional metallic loop like accessory worn on human body has an additional effect. Results have been shown that the SAR inside the human body increased due to the presence of metallic loop like accessory. Nevertheless, the SAR values are varying depending on the distance between the antenna and metallic loop like accessory. This concludes that the metallic loop-like accessory affects the SAR and the reflection coefficient of the planar wearable textile monopole. The variation of SAR value is possibly caused by the variation position and also the antenna orientation.

\section{Acknowledgements}

No potential conflict of interest was reported by the authors.

\section{References}

[1] M. Safari and A. Abdolali, "Dental Implants and Mobile-Phone Use," IEEE Antennas Propag. Mag., no. August 2016, pp. 43-51, 2016.

[2] C. Zhu, D. Wu, L. Ping, and W. Liang, "The Effects of Head Parameters on the Specific Absorption Rate in the Human Head," no. Bmei, pp. 423-427, 2015.

[3] S. H. Ronald, M. F. A. Malek, S. I. S. Hassan, C. E. Meng, M. H. Mat, M. S. Zulkefli, and S. F. Maharimi, "Designing Asian-Sized Hand Model for SAR Determination at GSM900/1800: Simulation Part," Prog. Electromagn. Res., vol. 129, no. May, pp. 439-467, 2012.

[4] P. J. Soh, G. A. E. Vandenbosch, F. H. Wee, A. Van Den Bosch, M. Martínez-vázquez, and D. Schreurs, "Specific Absorption Rate ( SAR ) Evaluation of Textile Antennas," vol. 57, no. 2, pp. 229-240, 2015.

[5] J. K. and R. lappalainen H Virtanen, "The effect of authentic metallic implants on the SAR distribution of the head exposed to 900,1800 and $2450 \mathrm{MHz}$ dipole near field," Phys. Med. Biol., vol. 52, 2007.

[6] W. G. Whittow, R. M. Edwards, C. J. Panagamuwa, and J. C. Vardaxoglou, "Effect of tongue jewellery and orthodontist metallic braces on the sar due to mobile phones in different anatomical human head models including children," 2008 Loughbrgh. Antennas Propag. Conf. LAPC, no. March, pp. 293 296, 2008

[7] N. Vidal and J. M. López-Villegas, "Changes in 
electromagnetic field absorption in the presence of subcutaneous implanted devices: Minimizing increases in absorption," IEEE Trans. Electromagn. Compat., vol. 52, no. 3, pp. 545-555, 2010.

[8] W. G. Whittow, C. J. Panagamuwa, R. M. Edwards, and J. C. Vardaxoglou, "The energy absorbed in the human head due to ring-type jewelry and faceilluminating mobile phones using a dipole and a realistic source," IEEE Trans. Antennas Propag., vol. 56, no. 12, pp. 3812-3817, 2008.

[9] K. Shiba, N. Elina, B. Zulkifli, and Y. Ishioka, "Analysis of specific absorption rate and internal electric field in human biological tissues surrounding an air-core coil-type transcutaneous energy transmission transformer," J. Artif. Organs, vol. 20, no. 2, pp. 103-109, 2017.

[10] D. Jovanovic, D. Krstic, V. Markovic, N. Cvetkovic, and V. Stankovic, "International Journal of Heat and Mass Transfer Temperature distribution and Specific Absorption Rate inside a child 's head," vol. 104, pp. 559-565, 2017.

[11] J. M. George, "A Review on SAR Reduction Methods Used For Mobile Application," IOSR J. Electron. Commun. Eng. Ver. II, vol. 10, no. 5, pp. 2278-2834, 2015.

[12] H. A. Rahim, M. Abdulmalek, P. J. Soh, K. A. Rani, N. Hisham, and G. A. E. Vandenbosch, "SubjectSpecific Effect of Metallic Body Accessories on Path Loss of Dynamic on-Body Propagation Channels," Sci. Rep., vol. 6, no. July, p. 29818, 2016.

[13] H. A. Rahim, M. Abdulmalek, P. J. Soh, and G. A. E. Vandenbosch, "Evaluation of a broadband textile monopole antenna performance for subject-specific on-body applications," Appl. Phys. A, vol. 123, no. 1, p. $97,2017$. 